Check for updates

Cite this: RSC Adv., 2019, 9, 13378

Received 27th December 2018

Accepted 9th April 2019

DOI: 10.1039/c8ra10595b

rsc.li/rsc-advances

\section{The influence of organically intercalated montmorillonites on the interfacial tension and structure of oil-in-water nanoemulsions $\dagger$}

\author{
Fangfang Peng, (D) Yangchuan Ke, DD * Yi Zhao, Xu Hu and Xi Zhao
}

The properties of $\mathrm{O} / \mathrm{W}$ emulsions can be improved by the addition of nanomaterials. To explore the influence of organically intercalated montmorillonites (OMts) on the properties of O/W emulsions, we introduced an OMt into a nanoemulsion as a co-stabilizer with the quaternary ammonium Gemini cationic surfactant (G16-2-16) and nonionic lauryl polyoxyethylene ether (Brij 30). The influence of the organically intercalated montmorillonite (OMt) on the properties, such as the interfacial tension, zeta potential, stability, conductivity and morphology of the droplets, of the nanoemulsions was investigated. The results indicate obvious synergistic effects of OMt with G16-2-16. At the concentration of 0.15\% w/v G16-2-16, ultralow interfacial tension (IFT) of the O/W results in the formation of nanoemulsions in a much shorter time with $3.4 \times$ $10^{-3} \% \mathrm{w} / \mathrm{v}$ OMt than that in the case of without OMt; however, at the concentration of $0.2 \% \mathrm{w} / \mathrm{v}$ G16-2-16, the interfacial tension of the O/W increased upon the addition of $3.4 \times 10^{-3} \% \mathrm{w} / \mathrm{v} \mathrm{OMt}$. In addition, light transmission measurements showed that the transmission of the nanoemulsions varied with temperature, and the process was reversible. The mechanisms of these phenomena were analyzed and confirmed by TEM.

\section{Introduction}

Nanoemulsions are dispersions of oil in water or water in oil with the general size range of 50-200 nm. Unlike microemulsions, nanoemulsions are not thermodynamically stable. However, nanoemulsions typically have long-term kinetic stability that allows them to resist aggregation and overcome gravity because of their small droplet dimensions. ${ }^{\mathbf{1 , 2}}$ Due to their potential advantages over conventional emulsions, nanoemulsions have attracted significant attention in the food, ${ }^{3}$ cosmetic, $^{4}$ and pharmaceutical industries ${ }^{5,6}$ as well as in enhanced oil recovery (EOR). ${ }^{7-12}$ It has been proposed that the properties of emulsions can be enhanced using nanoparticles. ${ }^{10,13,14} \mathrm{Pei}^{10}$ and N. Kumar ${ }^{13}$ investigated the synergistic effects of silica nanoparticles and surfactants in stabilizing the oil-in-water $(\mathrm{O} / \mathrm{W})$ emulsions. The results showed that the stability of the emulsion was enhanced by the addition of nanoparticles. Jahandideh et al. ${ }^{\mathbf{1 4}}$ investigated the effect of the nanoparticle/costabilizer synergy of graphene oxide-polyacrylamide on the stability of oil-in-water emulsions; they proposed that the localization of graphene oxide-polyacrylamide (GO-PAM) complexes and flocs at the interface significantly slowed down the creaming rates and enhanced the stability of the emulsion. Organically intercalated

College of Science, China University of Petroleum, Beijing, 102249, China. E-mail: kyc012@sohu.com

$\dagger$ Electronic supplementary information (ESI) available. See DOI: 10.1039/c8ra10595b montmorillonites (OMt) are another widely used nanomaterial. Natural montmorillonites are lamellar crystals that often exhibit platelet morphology. Since the interactions between layers in the $z$ direction are weak, they can undergo intercalation and exfoliation by guest molecules. ${ }^{15}$ In the past few decades, intercalated and exfoliated montmorillonites have been extensively used for the preparation of polymer nanocomposites. Currently, some studies have reported that these montmorillonites can also be used as stabilizers for emulsions due to their large-aspect-ratio plate-shaped particles that create a mechanical barrier to prevent coalescence. ${ }^{15-18}$ The morphology and the interactions of clay platelets with nanoemulsion droplets have also been investigated in previous studies. ${ }^{19-21}$ It has been reported that the distribution of clay platelets is influenced by their surface properties.

In this study, we aimed to investigate the influence of organically intercalated montmorillonites (OMt) on the properties of oil-in-water nanoemulsions. In previous studies, it has been reported that the stabilization of a nanoemulsion can be enhanced by cationic surfactants. ${ }^{22,23}$ Since these surfactants can also be used as an intercalation agent for montmorillonites, in this study, we have used a quaternary ammonium Gemini surfactant (G16-2-16) as an intercalation agent as well as an emulsion costabilizer with lauryl polyoxyethylene ether (Brij 30) and OMt. At first, we prepared O/W nanoemulsions using OMt-G16-2-16Brij 30 as stabilizers by the low-energy phase inversion composition (PIC) method. The experiments were performed using G162-16 at two different concentrations and OMt at three different concentrations. The concentrations of other components were 
fixed. Then, the properties, such as the droplet size, zeta potential, stability, interfacial tension and the morphology, of the nanoemulsions were systematically investigated. At last, the mechanism of the effect of the OMt on the interfacial tension and structure of the nanoemulsions was proposed.

\section{Experimental}

\section{Materials}

Lauryl polyoxyethylene ether (Brij 30, $M_{\mathrm{n}} \sim 362$ ) was purchased from Aladdin Industrial Corporation. Quaternary ammonium Gemini surfactant G16-2-16 (50 wt\% in water) was obtained from Daochun Chemical Technology Co. Ltd. Paraffin liquid $\left(d_{4}^{20}=0.835-\right.$ $0.855 \mathrm{~g} \mathrm{~cm}^{-3}$, c.p.) was obtained from Tianjin Fuchen Chemical Reagents Factory. Natural sodium montmorillonite (NaMMT) with the cationic exchange capacity (CEC) of $99.2 \mathrm{mmol} / 100 \mathrm{~g}$ was supplied by the Huai An Saibei Technology Co. Ltd. NaCl was obtained from Sinopharm Chemical Reagent Co. Ltd., China. Crude oil was produced in Panyu, Guangdong $\left(\rho=0.846 \mathrm{~g} \mathrm{~cm}^{-3}\right.$ and the equilibrium interfacial tension of $\mathrm{O} / \mathrm{W}$ was $6.558 \mathrm{mN} \mathrm{m}^{-1}$, as shown in Fig. S1 in the ESI†). Deionized water was used in this study.

\section{Preparation of the organically intercalated montmorillonite suspension}

The organically intercalated montmorillonite (OMt) suspension was prepared according to a previously reported protocol..$^{24,25}$ In a three-necked flask, $3.0 \mathrm{~g}$ of pristine montmorillonite (Na-MMT) was dispersed in $100 \mathrm{~mL}$ of deionized water for $30 \mathrm{~min}$. The intercalating agent G16-2-16 (0.4 g, equal to $\sim 0.27$ CEC) was dissolved in $25 \mathrm{~mL}$ of deionized water before its addition to a threenecked flask and then stirred for $8 \mathrm{~h}$ at $80^{\circ} \mathrm{C}$. To maintain the amphiphilicity of OMt and disperse it well in water, the amount of the cationic intercalant was set at $0.2 \mathrm{CEC}$; after completion of the cation exchange reaction, a part of the OMt suspension was filtered and dried under vacuum for XRD measurement; the remaining OMt suspension sample (solid content $=2.85 \% \mathrm{w} / \mathrm{v}$ ) was sealed and stored for emulsion preparation.

\section{Preparation of nanoemulsions}

Before emulsification, the surfactants Brij 30 (1.28 g) and G16-216 and the OMt aqueous suspension were dissolved in the oil phase (Paraffin liquid, $1.6 \mathrm{~g}$ ) under magnetic stirring. The surfactant-oil mixture and the $0.01 \mathrm{M} \mathrm{NaCl}$ aqueous solution (47 $\mathrm{mL}$ ) were separately placed in a water bath at $70{ }^{\circ} \mathrm{C}$. Then, the water phase was added dropwise to the surfactant-oil mixture solution in the water bath. After emulsification, the samples were cooled down at ambient temperature $\left(\sim 20^{\circ} \mathrm{C}\right)$. The composition of the nanoemulsions is presented in Table S1 in the ESI. $\dagger$ In this study, the OMt and surfactant concentrations were denoted as the mass percent per total sample volume $(\% \mathrm{w} / \mathrm{v})$.

\section{Characterization}

X-ray diffraction (XRD) patterns of the MMt and OMt samples were acquired via the Bruker D8 Advance X-ray diffractometer (STADI P, Germany) using nickel-filtered $\mathrm{Cu}-\mathrm{K} \alpha$ radiation $(\lambda=$ $0.154 \mathrm{~nm})$. The diffraction angle $(2 \theta)$ was set in the range from $1.5^{\circ}$ to $10^{\circ}$ at the scanning rate of $2^{\circ}$ per minute. The size and the zeta potential of the nanoemulsion droplets were measured by dynamic light scattering using Malvern Zetasizer Nano ZS, with the laser wavelength of $633 \mathrm{~nm}$ and the scanning angle of $173^{\circ}$ at $25 \pm 0.1{ }^{\circ} \mathrm{C}$. The Debye-Hückel equation was used to calculate the zeta potential from the mobility. The morphology of the nanoemulsions was investigated by TEM using the JEM-2100 (JEOL, Japan) transmission electron microscope. To facilitate the observation of the emulsion droplets, $2 \mathrm{wt} \%$ phosphotungstic acid salt solution was deposited on the dried TEM samples for negative dyeing. Then, 5 (2) drops of the nanoemulsion sample were added to $15 \mathrm{~mL}$ of deionized water before conducting the DLS (TEM) measurements. Turbiscan Lab Expert (Formulaction, France) was used to monitor the transmission signal of the nanoemulsions at different temperatures. The conductivity of the nanoemulsion was measured as a function of temperature using the Leici DDS-307A (INESA Scientific Instrument Co., Ltd, China) conductivity meter and a Pt/platinized electrode with the cell constant of 1.007. The interfacial tensions of the interfaces between crude oil and the nanoemulsions were determined by a pendant drop experiments at $45^{\circ} \mathrm{C}$ using the TX-500C interface tensiometer (Shanghai Zhongchen Digital Technology Equipment Co., Ltd., China).

\section{Results}

\section{XRD}

Fig. 1 displays the X-ray diffraction (XRD) patterns of the pristine Na-MMT and G16-2-16-intercalated OMt. The interlayer spacings of the Na-MMT and OMt were calculated according to the Bragg's equation. ${ }^{26}$

$$
2 d \sin \theta=n \lambda
$$

where $n$ is the reflection order $(n=1), \lambda$ is the wavelength of $\mathrm{X}$ rays, $d$ is the interlayer spacing $(\mathrm{nm})$ of the Na-MMT and OMt, and $2 \theta$ is the diffraction angle $\left(^{\circ}\right)$.

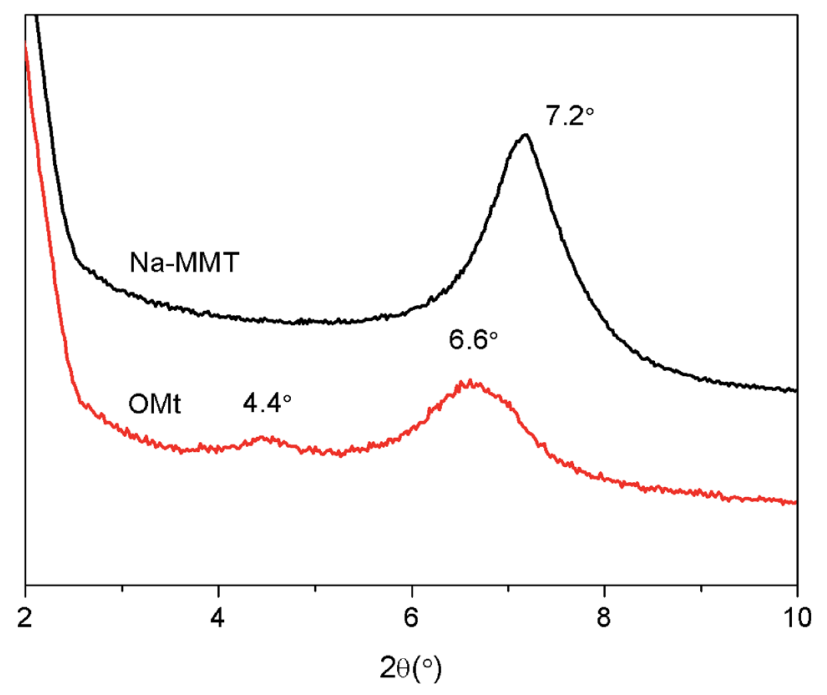

Fig. 1 XRD patterns of Na-MMT $\left(7.2^{\circ}, 1.23 \mathrm{~nm}\right)$ and $\mathrm{OMt}\left(6.6^{\circ}, 1.34 \mathrm{~nm}\right.$; $\left.4.4^{\circ}, 2.01 \mathrm{~nm}\right)$. 
The diffraction peak of Na-MMT is located at $2 \theta=7.2^{\circ}$, corresponding to the basal interlayer spacing of $1.23 \mathrm{~nm}$. The diffraction peaks of OMt are located at $2 \theta=6.6^{\circ}$ and $4.4^{\circ}$, corresponding to the basal interlayer spacings of 1.34 and $2.01 \mathrm{~nm}$. This result confirms that the interlayer spacing of $\mathrm{OMt}$ has increased.

\section{FTIR analysis}

FTIR spectra of the pristine Na-MMT and OMt are shown in Fig. 2. In both cases, the typical bands at $1008 \mathrm{~cm}^{-1}$ represent the $\mathrm{Si}-\mathrm{O}$ stretching vibrations, and the band at $3600 \mathrm{~cm}^{-1}$ corresponds to the $\mathrm{O}-\mathrm{H}$ stretching vibration of $\mathrm{Al}-\mathrm{OH}$ and $\mathrm{Si}-$ $\mathrm{OH}$ in the silicate layers. In Fig. 2b, OMt exhibits transmittance bands at $2850 \mathrm{~cm}^{-1}$ and $2926 \mathrm{~cm}^{-1}$ corresponding to the $-\mathrm{CH}_{2}$ stretching vibrations of the quaternary ammonium ions. These results indicate that the organic G16-2-16-modified (intercalated) montmorillonite (OMt) has been successfully prepared.

\section{Conductivity and zeta potential}

The effects of OMt on the conductivity of the nanoemulsions were investigated, as shown in Fig. 3. In both cases, in the tested temperature range $25-92{ }^{\circ} \mathrm{C}$, the conductivity underwent a drastic decrease to a minimum value and then increased with an increase in temperature. For the nanoemulsions with $0.15 \%$ w/v G16-2-16 (Fig. 3a), the minimum value of conductivity was reached in the range of $65-70{ }^{\circ} \mathrm{C}$. For the nanoemulsions with $0.20 \% \mathrm{w} / \mathrm{v}$ G16-2-16 (Fig. 3b), the minimum value of conductivity was achieved at higher temperatures (around $80{ }^{\circ} \mathrm{C}$ ). The effects of temperature on the conductivity of nanoemulsions have also been discussed in previous studies. ${ }^{27,28}$ With an increase in temperature, the nonionic Brij 30 became more lipophilic and led to an increase in size of the non-conducting oil droplets. Consequently, the $\mathrm{NaCl}$ concentration was diluted by a factor $(1$ $\left.-\phi_{0}\right)$, and, additionally, the conduction of small ions was obstructed by the non-conducting droplets; this resulted in a significant decrease in conductivity. With a further increase in temperature up to $90{ }^{\circ} \mathrm{C}$, the conductivities of all the nanoemulsions were observed to rapidly increase above the minimum

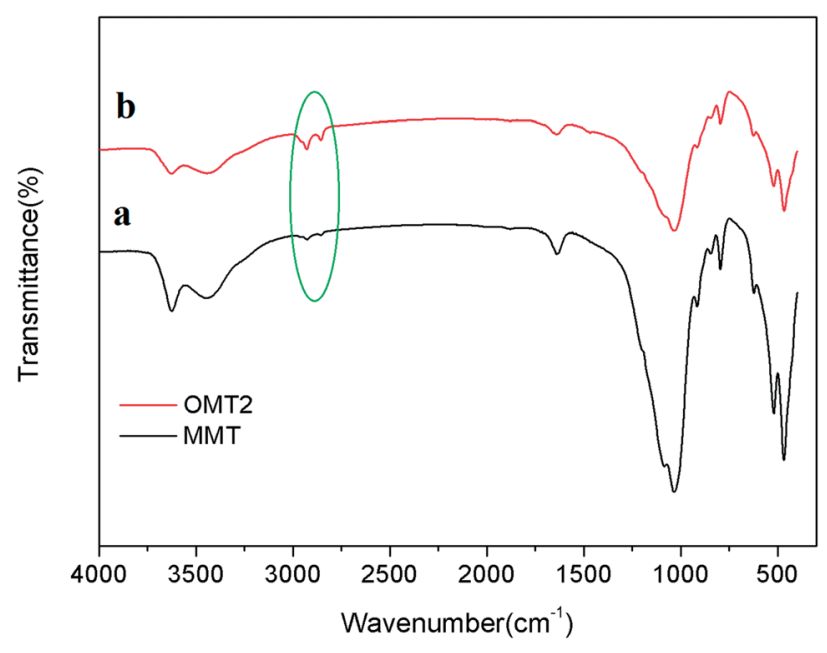

Fig. 2 FTIR spectra of (a) Na-MMT and (b) OMt. values. This may be attributed to the fact that the structure of the nanoemulsions changes to a bicontinuous structure. In addition, note that the conductivity values for the nanoemulsions with $0.15 \% \mathrm{w} / \mathrm{v}$ and $0.20 \% \mathrm{w} / \mathrm{v}$ G16-2-16 at the minimum point varied with the increasing OMt loading. This indicates a different interaction of the OMt with the surfactants and the droplets, and the mechanism of this phenomenon needs further investigation.

The zeta potential of the nanoemulsions was determined by DLS using the Malvern Zetasizer ZS instrument at $25{ }^{\circ} \mathrm{C}$, as shown in Fig. 4 and Table S1 (ESI $\dagger$ ). When the zeta potentials of the nanoemulsions with different concentrations of G16-2-16 and OMt were compared, a common feature was observed: all the nanoemulsions were positively charged. The variation trend of the zeta potential curves for the two G16-2-16 concentrations is similar with the increasing OMt loading, as seen in Fig. 4. Specifically, the zeta potential of the nanoemulsions with $0.20 \%$ w/v G16-2-16 was higher than that of the nanoemulsions with $0.15 \% \mathrm{w} / \mathrm{v}$ G16-2-16, which was positively correlated with conductivity. With an increase in the OMt loading, the zeta potential first undergoes an increase and then decreases with the further addition of OMt. The zeta potential reaches a maximum value at the OMt loading of $1.7 \times 10^{-3} \% \mathrm{w} / \mathrm{v}$. When the addition amount of OMt reached $6.8 \times 10^{-3} \% \mathrm{w} / \mathrm{v}$, the zetapotential of the nanoemulsions showed a slight increase again. The addition of nanoparticles increased the absolute value, and this phenomenon was also described in other study. ${ }^{12}$

\section{Emulsion morphology characterization}

The morphology of the nanoemulsions (at $\sim 25{ }^{\circ} \mathrm{C}$ ) was investigated by TEM, as shown in Fig. 5 . For the nanoemulsions without OMt (Fig. 5a and d), the oil droplets were spherical, and the diameter of the droplets was in the range of 25-30 $\mathrm{nm}$. Upon adding a small amount of OMt $\left(3.4 \times 10^{-3} \% \mathrm{w} / \mathrm{v}\right)$ to the nanoemulsions with $0.15 \%$ w/v G16-2-16 (Fig. 5b), the nanoemulsion maintained a spherical structure, and the size became slightly bigger than that of the nanoemulsion without the OMt. For the nanoemulsion with $0.20 \% \mathrm{w} / \mathrm{v}$ G16-2-16 (Fig. 5e), the oil droplets maintained a spherical structure with enriched exfoliated OMt dispersed on the oil droplets and between the inter-space of the oil droplets; we hypothesized that the OMt platelets were exfoliated in situ during nanoemulsion preparation; upon the addition of more OMt $\left(6.8 \times 10^{-3} \% \mathrm{w} / \mathrm{v}\right)$ to the nanoemulsions with $0.15 \%$ w/v G16-2-16 (Fig. 5c), the size of the oil droplets decreased; this could be attributed to extrusion by the OMt lamellar layers distributed in the droplet inter-space during water evaporation. For the nanoemulsions with $0.20 \% \mathrm{w} / \mathrm{v}$ G16-2-16 (Fig. 5f), a further increase in the amount of OMt resulted in the aggregation of the oil droplets into larger spherical clusters.

\section{Droplet size and long-term stability}

The droplet size and distributions in the nanoemulsions with varying OMt and surfactant concentrations were determined by dynamic light scattering (DLS) using the Malvern Zetasizer ZS instrument at $25{ }^{\circ} \mathrm{C}$, and the results are shown in Fig. 6. For the nanoemulsions with $0.15 \%$ w/v G16-2-16, as shown in Fig. 6a, the average diameter and particle dispersion index (PDI) 


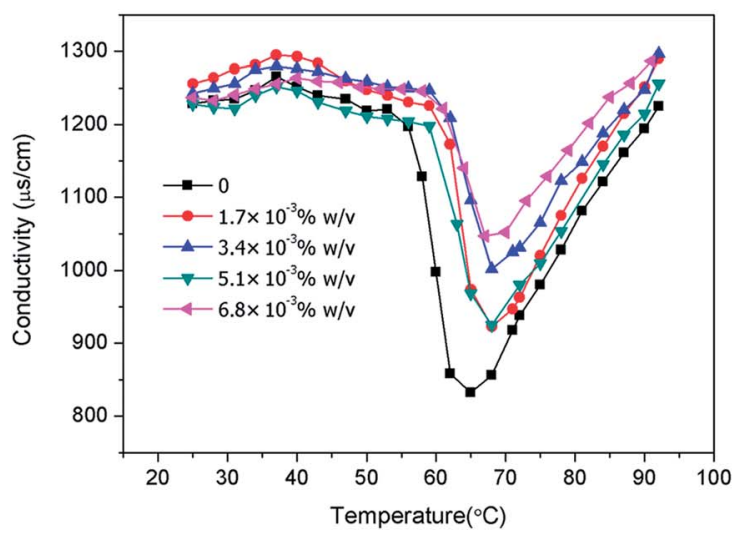

(a)

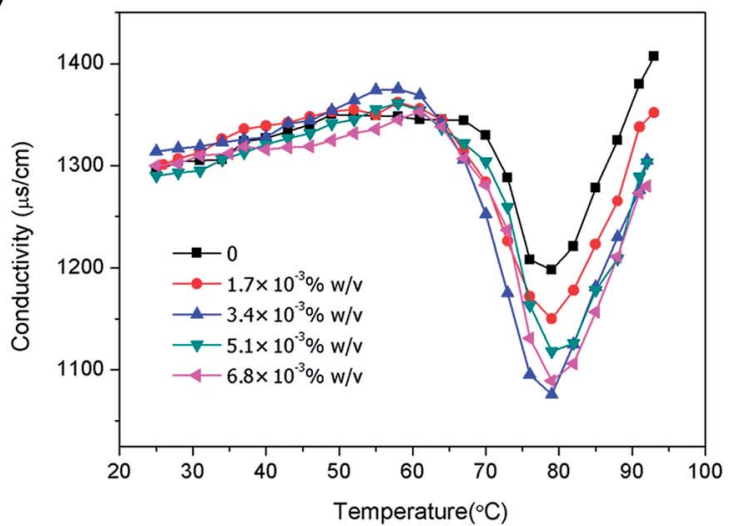

(b)

Fig. 3 Conductivity of the nanoemulsions with (a) $0.15 \%$ w/v G16-2-16, and (b) $0.20 \% \mathrm{w} / \mathrm{v}$ G16-2-16 at different OMt loadings as a function of temperature. The lines are used as a guide to the eye.

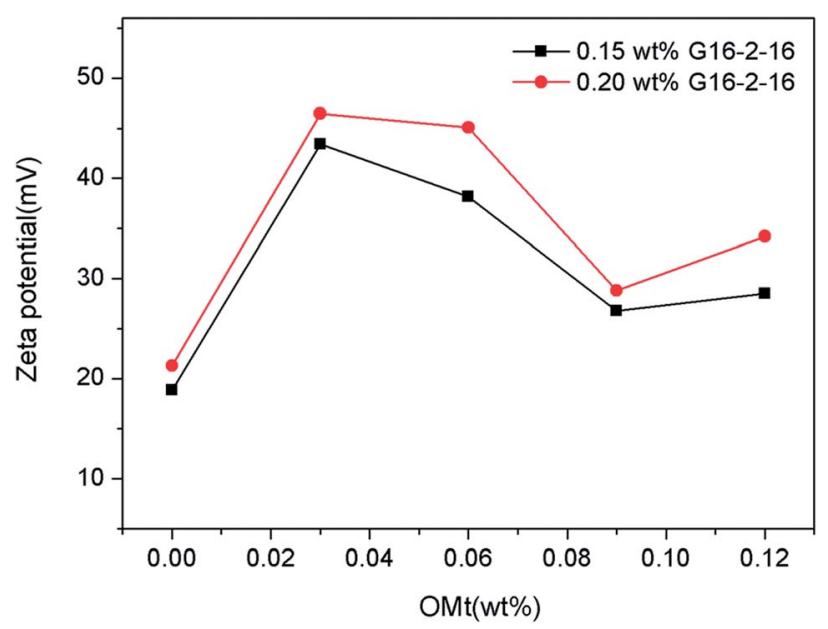

Fig. 4 Zeta potential of the nanoemulsion measured by dynamic light scattering (DLS). gradually increased with an increase in the amounts of OMt. For the nanoemulsions with $0.20 \% \mathrm{w} / \mathrm{v}$ G16-2-16 (Fig. 6b), the average diameter and particle dispersion index (PDI) increased significantly with the addition of OMt. We can see that the result of DLS is consistent with the result of TEM. After storage for 90 days, a white floccule was observed on top of all the nanoemulsions. For the nanoemulsions with OMt, the white floccules were more obvious, indicating that a creaming process had occurred (Fig. S2 $\dagger$ ). Furthermore, for the nanoemulsions with $0.15 \% \mathrm{w} / \mathrm{v}$ G16-2-16 and $3.4 \times 10^{-3} \% \mathrm{w} / \mathrm{v}$ OMt, a white precipitate could be observed at the bottom of the bottle. By combining these results with those of the TEM, we can deduce that the white precipitate is OMt dispersed in the bulk phase. The samples were then shaken and diluted with water, and then, size measurements were conducted to evaluate the longterm stability of the nanoemulsion. Fig. 7a and $b$ show the comparison between the nanoemulsion (with 0 and $3.4 \times$ $10^{-3} \% \mathrm{w} / \mathrm{v} \mathrm{OMt}$ ) droplet sizes for the newly prepared nanoemulsion and that stored for 90 days, and the results show that the droplet sizes for all the nanoemulsions significantly

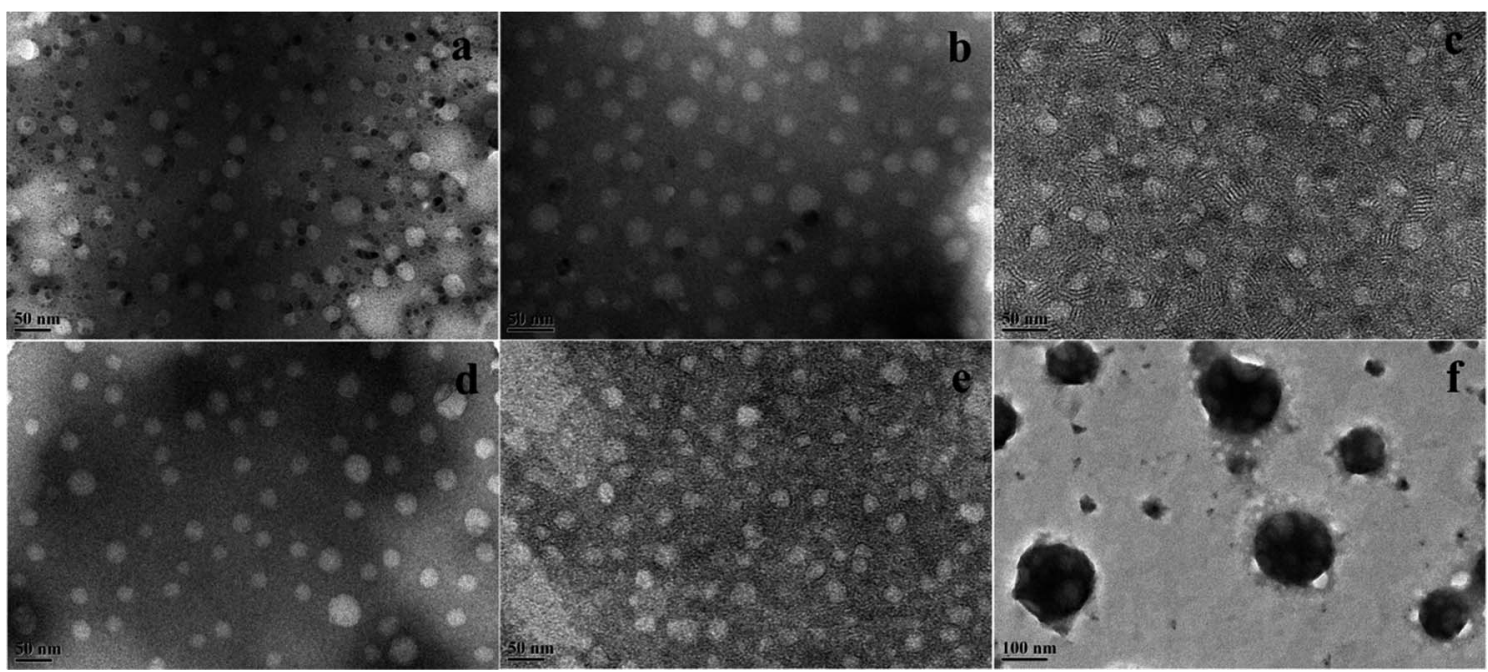

Fig. 5 TEM images of the nanoemulsions with 0.15\% w/v G16-2-16 and (a) without OMt (b), $3.4 \times 10^{-3} \% \mathrm{w} / \mathrm{v}$ OMt, and (c) $6.8 \times 10^{-3} \% \mathrm{w} / \mathrm{v}$ OMt; nanoemulsions with $0.20 \% \mathrm{w} / \mathrm{v}$ G16-2-16 and (d) without OMt, (e) $3.4 \times 10^{-3} \% \mathrm{w} / \mathrm{v} \mathrm{OMt}$, and (f) $6.8 \times 10^{-3} \% \mathrm{w} / \mathrm{v} \mathrm{OMt}\left(25{ }^{\circ} \mathrm{C}\right)$. 


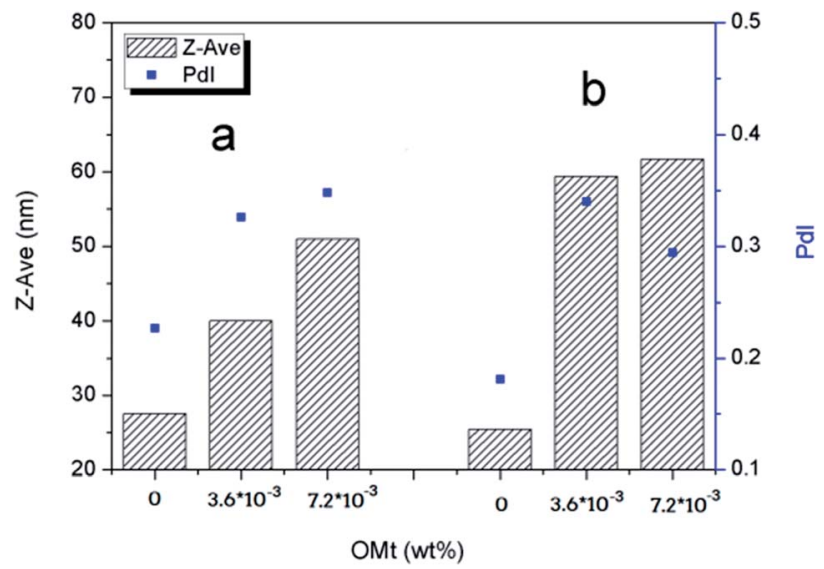

Fig. 6 Z-Average diameter and the polydispersity index (PDI) of the nanoemulsions measured by the DLS method.

increase after storage for 90 days. This indicated that the Ostwald ripening process had occurred, and we deduced that the creaming process was caused by Ostwald ripening.

\section{Interfacial tension}

The interfacial tensions (IFTs) of the nanoemulsions as a function of time were measured at $45^{\circ} \mathrm{C}$, and the results are shown in Fig. 8. For the systems with $0.15 \%$ w/v G16-2-16, the interfacial tension of the oil/nanoemulsion reduced at a much more rapid rate upon the addition of $3.4 \times 10^{-3} \% \mathrm{w} / \mathrm{v}$ OMt. In only $\sim 900 \mathrm{~s}$, ultralow interfacial tension $\left(10^{-3} \mathrm{mN} \mathrm{m}^{-1}\right)$ could be achieved; on further increasing the OMt addition amount to 6.8 $\times 10^{-3} \% \mathrm{w} / \mathrm{v}$, the rate of reduction of the interfacial tension of the nanoemulsion reduced; however, the equilibrium interfacial tension was still lower than that of the emulsion without OMt (Fig. 8a). For the systems with $0.20 \%$ w/v G16-2-16, the nanoemulsion with the loading of $3.4 \times 10^{-3} \% \mathrm{w} / \mathrm{v}$ OMt retained the highest interfacial tension value over the whole test (2000 s, Fig. 8b) as compared to the emulsions with 0 and $6.8 \times$ $10^{-3} \% \mathrm{w} / \mathrm{v}$ OMt.

Upon comparing the nanoemulsion with $0.15 \mathrm{wt} \%$ and that with $0.20 \mathrm{wt} \%$ G16-2-16, it was found that the former displayed lower interfacial tension value at equilibrium (Table S2 in the ESI $\dagger$ ); to confirm these results, the interfacial tension
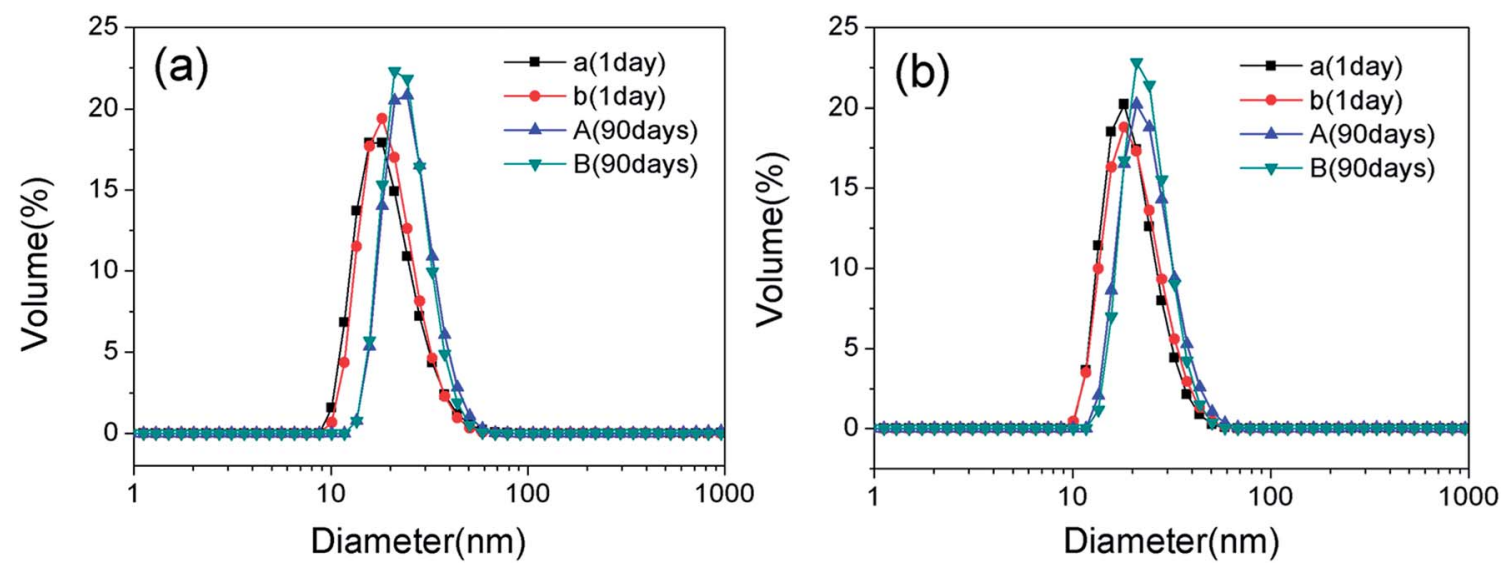

Fig. 7 Nanoemulsion droplet sizes measured by DLS. (a) Size variation of the nanoemulsions with $0.15 \%$ w/v G16-2-16 stored for 1 day and 90 days ( $\left(\mathrm{a}\right.$ and $\mathrm{A}$ ) without OMt; ( $\mathrm{b}$ and $\mathrm{B}$ ) with $3.4 \times 10^{-3} \% \mathrm{w} / \mathrm{v} \mathrm{OMt)}$; $(\mathrm{b})$ size variation of the nanoemulsions with $0.20 \% \mathrm{w} / \mathrm{v}$ G16-2-16 stored for 1 day and 90 days ((a and $\mathrm{A})$ without $\mathrm{OMt}$; ( $\mathrm{b}$ and $\mathrm{B})$ with $\left.3.4 \times 10^{-3} \% \mathrm{w} / \mathrm{v} \mathrm{OMt}\right)$.

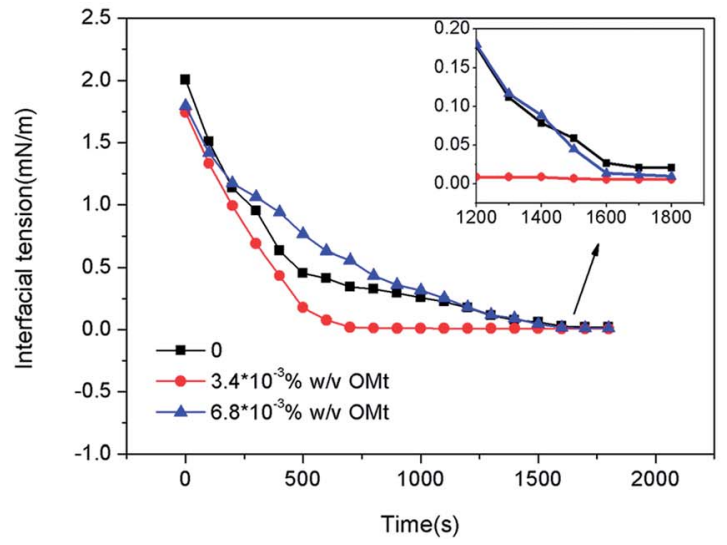

(a)

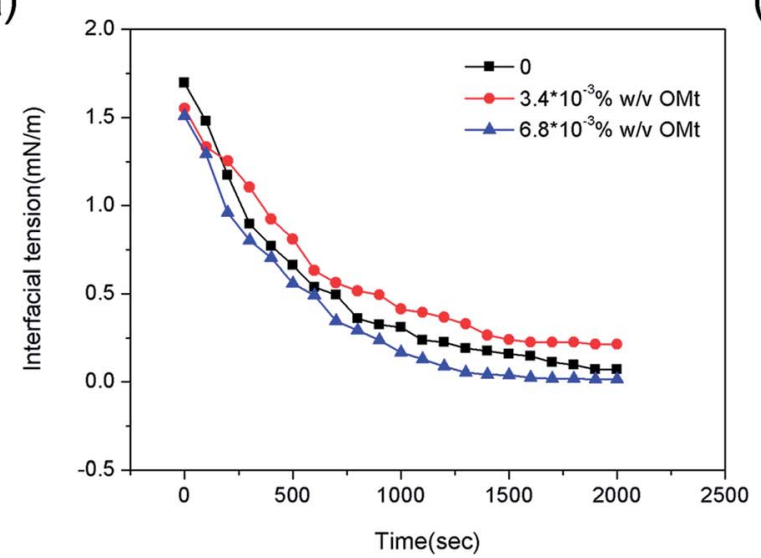

(b)

Fig. 8 Interfacial tension of the crude oil/nanoemulsions with (a) $0.15 \mathrm{wt} \%$ and (b) $0.20 \mathrm{wt} \% \mathrm{G} 16-2-16$ as a function of time at $45^{\circ} \mathrm{C}$, the inset plot show partial enlargement of (a). 

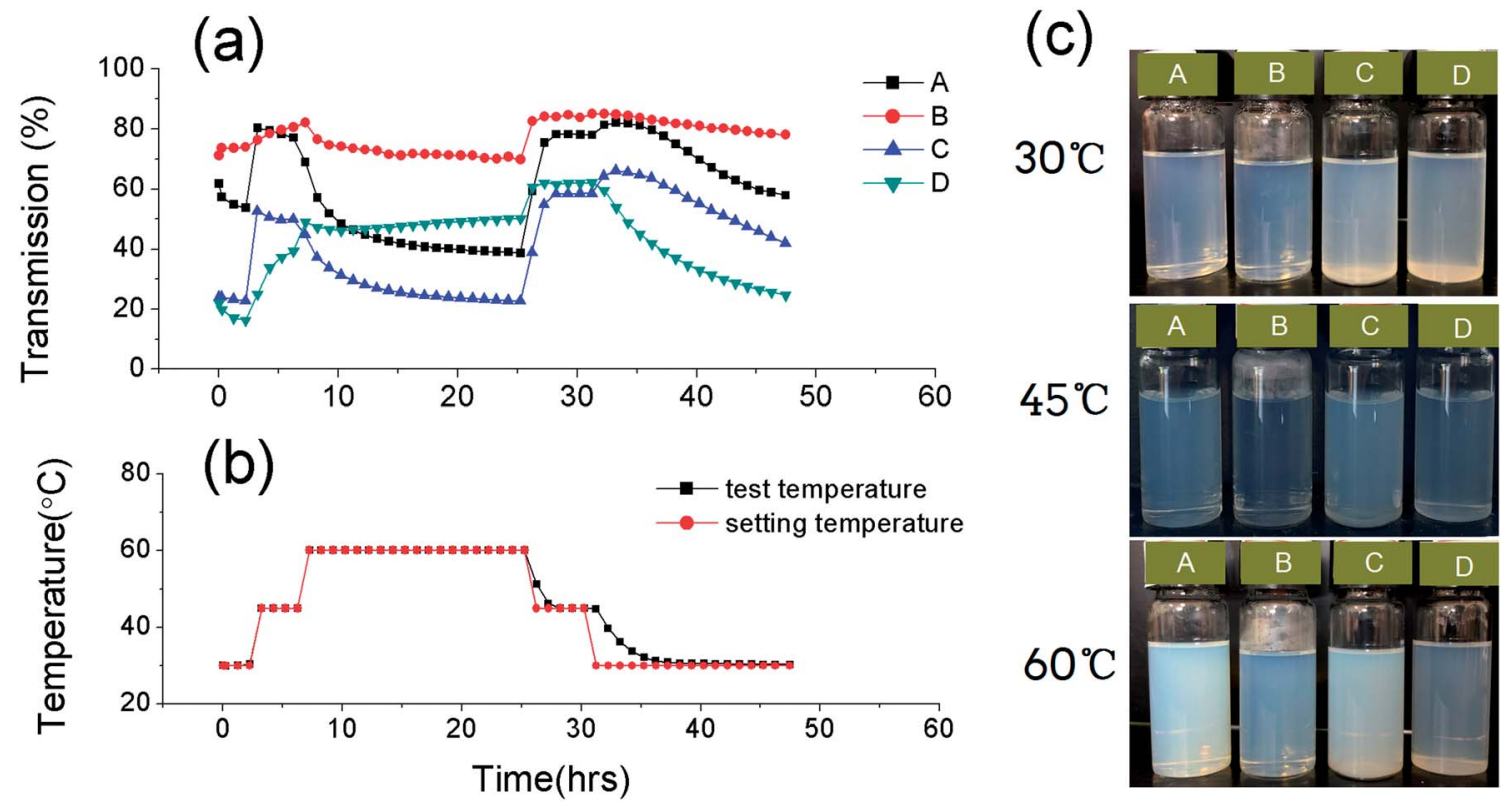

Fig. 9 (a) Light transmission of the nanoemulsions varied with time, (b) setting and test measurement temperature varied with time and (c) images of the nanoemulsions at different temperatures ((A) nanoemulsions with 0.15\% w/v G16-2-16, (B) nanoemulsions with 0.20\% w/v G16-216, (C) nanoemulsions with $0.15 \% \mathrm{w} / \mathrm{v}$ G16-2-16 + 3.4 × 10-3\% w/v OMt, (D) nanoemulsions with $0.20 \% \mathrm{w} / \mathrm{v} \mathrm{G} 16-2-16+3.4 \times 10^{-3} \% \mathrm{w} / \mathrm{v}$ OMt).

measurement for each nanoemulsion was repeated, and the results showed good reproducibility.

\section{Light transmission variation with temperature}

During the experiment, we observed that the light transmission of the nanoemulsions varied with temperature, and the process of transmission variation was reversible. To better observe the transmission variations, we used Turbiscan Lab Expert (Formulaction, France) to monitor the transmission signal of the nanoemulsions at different temperature. The measurement principle has been stated in previous studies. ${ }^{29,30}$ The transmission profile of the nanoemulsions is shown in Fig. 9. The horizontal axis represents measurement time (in hours), and the vertical axis represents the intensity of light transmission in percentage (Fig. 9a) and the measurement temperature (Fig. 9b). For all the nanoemulsions, it is obvious that the transmission of the nanoemulsions has a maximum value around $45{ }^{\circ} \mathrm{C}$. For the curves $\mathrm{A}$ and $\mathrm{C}$, the intensity of the transmission underwent a significant increase as the temperature increased from 30 to $45^{\circ} \mathrm{C}$; however, for the curves B and D, as the temperature increased from 30 to $45^{\circ} \mathrm{C}$, the transmission variation was not very evident.

To explore the interaction of the OMt with the nanoemulsion droplets, we conducted TEM measurements of the nanoemulsions at $45{ }^{\circ} \mathrm{C}$ and $60{ }^{\circ} \mathrm{C}$. Before TEM measurements, the nanoemulsions were equilibrated at $45^{\circ} \mathrm{C}$ and at $60^{\circ} \mathrm{C}$ for $20 \mathrm{~h}$. The TEM results are shown in Fig. 10 and 11. For the nanoemulsions without OMt (Fig. 10a, b and 11a, b), we can see that the droplet size of the nanoemulsions increases with the increasing temperature, and the droplets maintain their spherical shape. We deduced that this was due to the Brij 30 solute in the oil droplets. The results of the light transmission suggest that the droplets of the nanoemulsions achieve minimum size at $45{ }^{\circ} \mathrm{C}$. It can be determined that the nanoemulsions in water are formed by two parts, i.e., the oil droplets and the hydrophilic surface. For the nanoemulsions with $3.4 \times$ $10^{-3} \% \mathrm{w} / \mathrm{v}$ OMt (Fig. 10c, d and 11c, d), the microstructures were quite different. Specifically, for the nanoemulsions with $0.15 \% \mathrm{w} / \mathrm{v} \mathrm{G} 16-2-16$ at $45{ }^{\circ} \mathrm{C}$, some of the droplets were joined together by the OMt layers; this resulted in a change in the shape of the droplets. As the temperature increased to $60{ }^{\circ} \mathrm{C}$, more OMt layers adsorbed on the droplets, and the spherical droplets were elongated. For the nanoemulsions with $0.20 \% \mathrm{w} / \mathrm{v}$ G16-2-16 at $45{ }^{\circ} \mathrm{C}$, most of the OMt layers were adsorbed on the oil droplets, and the size of the droplets seemed unchanged. On further increasing the temperature to $60{ }^{\circ} \mathrm{C}$, the size of the

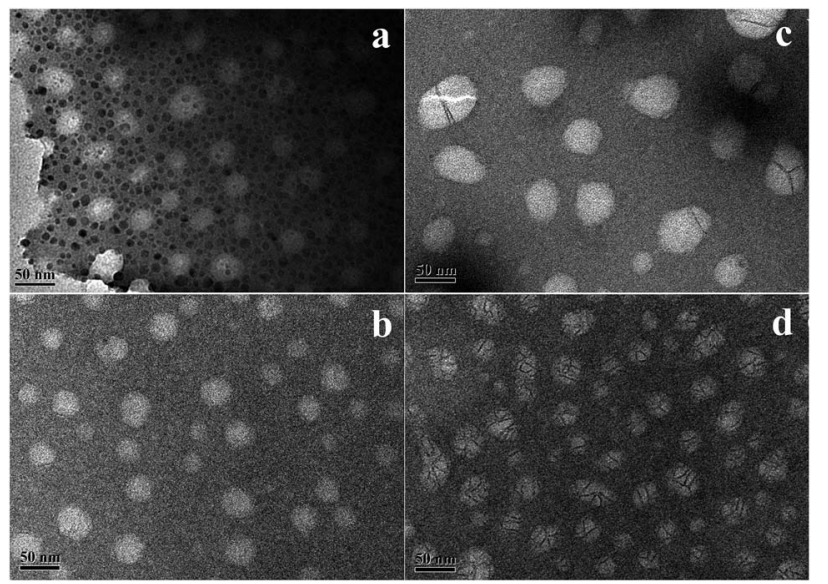

Fig. 10 TEM images of the nanoemulsions equilibrated at $45^{\circ} \mathrm{C}$ for $20 \mathrm{~h}$. 


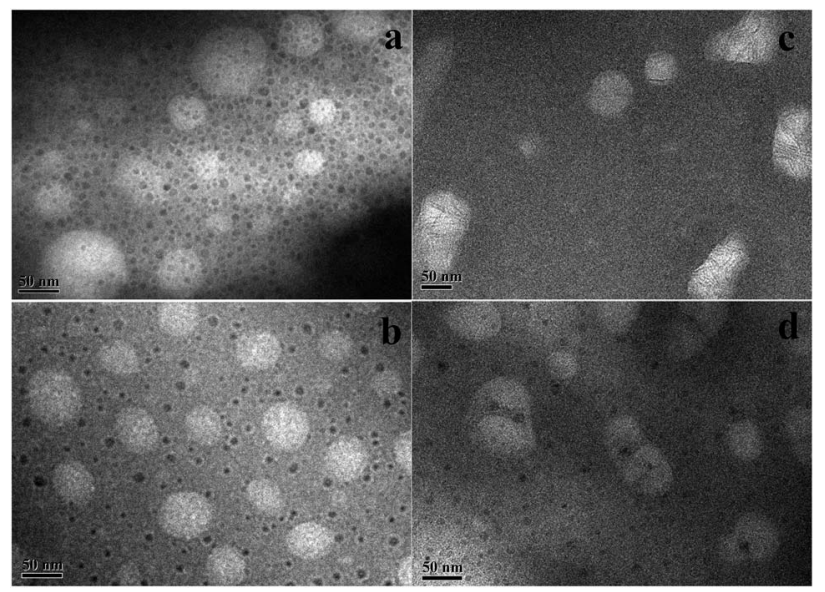

Fig. 11 TEM images of the nanoemulsions equilibrated at $60{ }^{\circ} \mathrm{C}$ for $20 \mathrm{~h}$ ((a) nanoemulsions with $0.15 \%$ w/v G16-2-16, (b) nanoemulsions with $0.20 \%$ w/v G16-2-16, (c) nanoemulsions with $0.15 \%$ w/v G16-2$16+3.4 \times 10^{-3} \% \mathrm{w} / \mathrm{v}$ OMt, d: nanoemulsions with $0.20 \%$ w/v G16-2$16+3.4 \times 10^{-3} \% \mathrm{w} / \mathrm{v} \mathrm{OMt}$ ).

droplets increased significantly, and the OMt distributed on the droplets before immediately gathering in the middle of the droplets; next, by combining the results of the interfacial tension measurements, TEM, and previously reported studies, ${ }^{19-21}$ we could conclude that certain HLB of OMt might act as particle surfactants that absorbed on the crude oil/water interface and significantly reduced the interfacial tension (similar to the case of the nanoemulsion C). In other situations, the OMt may prefer to absorb on the surface of the droplets of the nanoemulsion and consume more surfactant such as in the case of nanoemulsion $\mathrm{D}$; this results in an increase in the crude oil/water interfacial tension.

\section{Conclusions}

Herein, positively charged nanoemulsions stabilized by mixed cationic-nonionic surfactants and OMt were prepared by a lowenergy PIC method. The influence of organically intercalated montmorillonites on the interfacial tension and the microstructure of the $\mathrm{O} / \mathrm{W}$ nanoemulsions was investigated. The weak surfactant-NP interaction affects the microstructure of the nanoemulsions and results in a change in their properties such as the $\mathrm{O} / \mathrm{W}$ interfacial tension, zeta potential, conductivity, and micro-structure. At the concentration of $0.15 \% \mathrm{w} / \mathrm{v}$ G16-216, an ultralow interfacial tension (IFT) of $\mathrm{O} / \mathrm{W}$ could be achieved in a much shorter time for the nanoemulsions with $3.4 \times$ $10^{-3} \% \mathrm{w} / \mathrm{v}$ OMt than for those without OMt. However, at the concentration of $0.2 \% \mathrm{w} / \mathrm{v} \mathrm{G} 16-2-16$, the interfacial tension of $\mathrm{O} /$ $\mathrm{W}$ increased upon the addition of $3.4 \times 10^{-3} \% \mathrm{w} / \mathrm{v}$ OMt. In addition, light transmission measurements showed that the transmission of the nanoemulsions varied with temperature, and the process was reversible. The mechanisms of these phenomena were analyzed and confirmed by TEM. The synergistic effects of OMt with the G16-2-16 surfactant may have significant potential applications in the field of enhanced oil recovery.

\section{Conflicts of interest}

There are no conflicts to declare.

\section{Acknowledgements}

This work was financially supported by the National Natural Science Foundation of China (Grant No. 51674270), National Major Project (Grant No. 2017ZX05009-003), Major project of the National Natural Science Foundation of China (No. 51490650), and the Foundation for Innovative Research Groups of the National Natural Science Foundation of China (Grant No. 51821092, 51521063).

\section{References}

1 D. J. McClements and H. Xiao, Potential biological fate of ingested nanoemulsions: influence of particle characteristics, Food Funct., 2012, 3(3), 202-220.

2 T. Tadros, P. Izquierdo, J. Esquena and C. Solans, Formation and stability of nano-emulsions, Adv. Colloid Interface Sci., 2004, 108-109, 303-318.

3 M. Wulff-Pérez, A. Torcello-Gómez, M. J. Gálvez-Ruíz and A. Martín-Rodríguez, Stability of emulsions for parenteral feeding: Preparation and characterization of $\mathrm{o} / \mathrm{w}$ nanoemulsions with natural oils and Pluronic f68 as surfactant, Food Hydrocolloids, 2009, 23(4), 1096-1102.

4 M. N. Yukuyama, D. D. Ghisleni, T. J. Pinto and N. A. BouChacra, Nanoemulsion: process selection and application in cosmetics-a review, Int. J. Cosmet. Sci., 2016, 38(1), 13-24.

5 A. Gupta, H. B. Eral, T. A. Hatton and P. S. Doyle, Nanoemulsions: formation, properties and applications, Soft Matter, 2016, 12, 2826.

6 Y. Singh, J. G. Meher, K. Raval, F. A. Khan, M. Chaurasia, N. K. Jain and M. K. Chourasia, Nanoemulsion: Concepts, development and applications in drug delivery, $J$. Controlled Release, 2017, 252, 28-49.

7 A. Mandal, A. Bera, K. Ojha and T. Kumar, Characterization of Surfactant Stabilized Nanoemulsion and Its Use in Enhanced Oil Recovery, SPE155406, 2012.

8 H. H. Pei, G. C. Zhang, J. J. Ge, J. Zhang, Q. Zhang, and L. P. Fu, Investigation of Nanoparticle and Surfactant Stabilized Emulsion to Enhance Oil Recovery in Waterflooded Heavy Oil Reservoirs, SPE174488, 2015.

9 F. D. Qiu, The Potential Applications in Heavy Oil EOR With the Nanoparticle and Surfactant Stabilized Solvent-Based Emulsion, SPE134613, 2010.

10 H. Pei, G. Zhang, J. Ge, J. Zhang and Q. Zhang, Investigation of synergy between nanoparticle and surfactant in stabilizing oil-in-water emulsions for improved heavy oil recovery, Colloids Surf., A, 2015, 484, 478-484.

11 N. Kumar and A. Mandal, Oil-in-water nanoemulsion stabilized by polymeric surfactant: Characterization and properties evaluation for enhanced oil recovery, Eur. Polym. J., 2018, 109, 265-276.

12 N. Kumar and A. Mandal, Surfactant Stabilized Oil-in-Water Nanoemulsion: Stability, Interfacial Tension, and Rheology 
Study for Enhanced Oil Recovery Application, Energy Fuels, 2018, 32, 6452-6466.

13 N. Kumar and A. Mandal, Thermodynamic and physicochemical properties evaluation for formation and characterization of oil-in-water nanoemulsion, J. Mol. Liq., 2018, 266, 147-159.

14 H. Jahandideh, P. Ganjeh-Anzabi, S. L. Bryant and M. Trifkovic, The Significance of Graphene OxidePolyacrylamide Interactions on the Stability and Microstructure of Oil-in-Water Emulsions, Langmuir, 2018, 34(43), 12870-12881.

15 A. F. Mejia, A. Diaz, S. Pullela, Y.-W. Chang, M. Simonetty, C. Carpenter, J. D. Batteas, M. S. Mannan, A. Clearfield and Z. Cheng, Pickering emulsions stabilized by amphiphilic nano-sheets, Soft Matter, 2012, 8(40), 1024510253.

16 J. Dong, A. J. Worthen, L. M. Foster, Y. Chen, K. A. Cornell, S. L. Bryant, T. M. Truskett, C. W. Bielawski and K. P. Johnston, Modified montmorillonite clay microparticles for stable oil-in-seawater emulsions, ACS Appl. Mater. Interfaces, 2014, 6(14), 11502-11513.

17 G. Lagaly, M. Reese and S. Abend, Smectites as colloidal stabilizers of emulsions I. Preparation and properties of emulsions with smectites and nonionic surfactants, Appl. Clay Sci., 1999, 14, 83-103.

18 G. Lagaly, M. Reese and S. Abend, Smectites as colloidal stabilizers of emulsions II. Rheological properties of smectite-laden Emulsions, Appl. Clay Sci., 1999, 14, 279-298.

19 Q. Sun, Y. Deng and Z. L. Wang, Synthesis and Characterization of Polystyrene-Encapsulated Laponite Composites via Miniemulsion Polymerization, Macromol. Mater. Eng., 2004, 289, 288-295.

20 N. Negrete-Herrera, J. L. Putaux and L. David, Polymer/ Laponite composite latexes: Particle morphology, film microstructure, and properties, Macromol. Rapid Commun., 2007, 28, 1567-1573.

21 N. Negrete-Herrera, J. L. Putaux and E. Bourgeat-Lami, Synthesis of polymer/Laponite nanocomposite latex particles via emulsion polymerization using silylated and cation-exchanged Laponite clay platelets, Prog. Solid State Chem., 2006, 34, 121-137.

22 Z. Mei, J. Xu and D. Sun, O/W nano-emulsions with tunable PIT induced by inorganic salts, Colloids Surf., A, 2011, 375(13), 102-108.

23 Z. Mei, S. Liu, L. Wang, J. Jiang, J. Xu and D. Sun, Preparation of positively charged oil/water nano-emulsions with a subPIT method, J. Colloid Interface Sci., 2011, 361(2), 565-572.

24 J. Q. Ji, Y. C. Ke, Y. Pei and G. L. Zhang, Effects of highly exfoliated montmorillonite layers on the properties of clay reinforced terpolymer nanocomposite plugging microspheres, J. Appl. Polym. Sci., 2017, 134, 44894.

25 M. Zanetti, S. Lomakin and G. Camino, Polymer layered silicate nanocomposites, Macromol. Mater. Eng., 2000, 279, 1-9.

26 X. Hu, Y. Ke, Y. Zhao, S. Lu, Q. Deng, C. Yu and F. Peng, Synthesis, characterization and solution properties of $\beta$ cyclodextrin-functionalized polyacrylamide/ montmorillonite nanocomposites, Colloids Surf., A, 2019, 560, 336-343.

27 R. Aveyard, B. P. Binks, P. D. I. Fletcher, C. E. Rutherford, P. J. Dowding and B. Vincent, Dissociation of AOT monolayers stabilising oil-in-water microemulsions in Winsor I systems, Phys. Chem. Chem. Phys., 1999, 1, 19711978.

28 N. P. Ashby and B. P. Binks, Pickering emulsions stabilised by Laponite clay particles, Phys. Chem. Chem. Phys., 2000, 2, 5640-5646.

29 D. D. Kaombe, M. Lenes, K. Toven and W. R. Glomm, Turbiscan as a Tool for Studying the Phase Separation Tendency of Pyrolysis Oil, Energy Fuels, 2013, 27(3), 14461452.

30 C. Carbone, T. Musumeci, M. R. Lauro and G. Puglisi, Ecofriendly aqueous core surface-modified nanocapsules, Colloids Surf., B, 2015, 125, 190-196. 